\title{
Opening the black box of collaborative writing: experiences from a teamwork-based course in industrial management
}

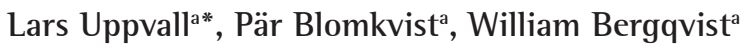

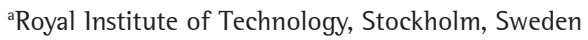 \\ *lars.uppvall@indek.kth.se
}

\begin{abstract}
In this paper we discuss the introduction of collaborative writing (CW) tools in a course designed with learning activities based on problem-based learning (PBL), authentic case methodology, and teamwork. We argue that CW is a vital, but poorly understood, part of teamwork, and a black-box activity. Our ambition is to open the black box of CW and discuss how CW concepts can enrich teamwork activities. We build on our students' reflections on challenges linked to CW in a teamwork setting. In total the data consisted of 77 individual reflection papers, which were analyzed using constructs from prior literature on CW. Our results show that our students actively used CW tools and strategies and that CW had a large impact-and, in fact, enhanced teamwork management. The CW tools also helped in creating sustainable teamwork in the sense that they enhanced the three criterions of team performance: productivity, cohesion, and learning.
\end{abstract}

Keywords

Active learning. Engineering education. Collaborative writing. Teamwork.

How to cite this article: Uppvall, L., Blomkvist, P., \& Bergqvist, W. (2017). Opening the black box of collaborative writing: experiences from a teamwork-based course in industrial management. Production, 27(spe), e20162220. http://dx.doi. org/10.1590/0103-6513.222016

\section{Introducing CW as an active learning component in the context of engineering education}

The high pace of change in many industries brings a number of new and enhanced challenges for engineering education (Berglund, 2012; Crawley et al., 2014; Edström \& Kolmos, 2014). In particular, modern industry has increasingly higher demands on engineers to work in teamwork-based projects, where collective text production is a central component (e.g., Gimenez \& Thondhlana, 2012). This has put a focus on what is actually done when creating a text in a teamwork setting, and thus, collaborative writing (CW) has been put on the industrial agenda.

In this paper we discuss the introduction of CW tools in a course in the industrial management master's program at the Royal Institute of Technology (KTH), Stockholm. By CW tools we mean concepts and methods that highlight the collective writing process (see chapter 3). The course where $\mathrm{CW}$ was introduced, in addition to the whole program, has been designed using learning activities from what we call our active learning package. This package consists of three elements: problem-based learning (PBL), authentic case methodology, and teamwork.

PBL is our pedagogical foundation, authentic case methodology is our way of implementing PBL, and teamwork is naturally an integrated part of both PBL and case methodology and, for obvious reasons, a central part of management education (Blomkvist \& Uppvall, 2012a, b). Teamwork knowledge is usually framed by concepts from the fields of project management and team leadership (e.g., Maylor, 2010; Thompson, 2011). Our students have general knowledge on how to lead, plan, and execute a teamwork-based project, but what about writing? What happens if a large part of a project is actually to write a collective report? 
We argue that CW is a vital, but poorly understood, part of teamwork and that CW is a black-box activity. Nearly every teamwork project includes CW, but no one really pays much attention to what is actually done when a text is produced in a team setting.

In this paper we present the results of an investigation of the implementation of CW tools as an extension of our active learning package. We want to open the black box of CW and discuss how CW concepts can enrich teamwork activities. We argue that CW in fact facilitates and enhances the quality of teamwork by making a large portion of the work explicit and open to reflect on. This means our approach to CW is somewhat different than might be expected. We have focused on the relationship between CW and teamwork rather than investigating whether or not CW tools help in creating better collective texts.

The two-year industrial management master's program (launched in 2010) admits 70-100 engineering bachelor's graduates per year (e.g., mechanical engineering, computer science, material design). Students come from BSc programs at KTH and through international admission. The program design has been strongly influenced by new approaches to engineering education aiming to strengthen student innovativeness, creativity, and ability to not only conceive and design but also to implement and operate e.g. products, processes, and systems-an approach referred to in the literature by the acronym CDIO (Blomkvist \& Uppvall, 2012a; Crawley et al., 2007; Crawley et al., 2014).

In this paper we focus on one specific course wherein active learning is especially prominent. The course is called Change Project in Industrial Management (CPIM). We discuss the introduction of CW tools in the CPIM course as well as how these tools influenced teamwork in the case assignment given to our students.

Subject-wise the program could be described as covering most of the primary and supporting activities of Porter's well-known value chain model (Porter, 1985), including leadership, functional, strategic, and industrial dynamic perspectives. Our students have the ability to handle large workloads; they are analytically skilled and trained in problem solving. However, industrial managers do not primarily solve problems; they formulate them. Therefore, our goal is to enhance the students' transition from problem solving to problem formulation. To foster this transition, we have, as mentioned, introduced an active learning package involving PBL, authentic case methodology, and teamwork, and before we explain the role of CW tools in the CPIM course, we will briefly present these central learning activities:

PBL is a well-known concept (e.g., Barrows \& Tamblyn, 1980; Biggs \& Tang, 2007; Cheong, 2008). Learning results from the students' struggle to absorb, understand, reformulate, and solve a complex real-world problem. In PBL the focus is on vaguely defined problem scenarios, and students are expected to engage in the complex situation presented and reach a problem formulation on their own. The bottom line in our version of PBL is aligned with our goal of turning problem solvers into problem formulators. We insist on presenting the students with vaguely structured problems and open-ended questions. Why? Because ill-structured problems prepare students for managerial positions.

Our second active learning activity is authentic case methodology. By using authentic cases we contend that there is a need for progression beyond predeveloped cases. Traditional case methodology is not enough to reach our learning objectives. We argue that authentic cases are a necessity when trying to turn problem solvers into problem formulators and that learning activities must encompass elements that bring a high degree of ambiguity to the problem setting.

The authentic case methodology is introduced early in the program and executed fully in CPIM, where we engage four companies as partners. All companies represent large industrial companies, all are global or Pan-Nordic, and all have a strong demand for industrial management competence.

The practical setup is quite complex. Each of the four companies we engage is assigned three student teams (6-8 students each). Thus, we have a total of 12 groups investigating change processes in four industrial areas. Each team receives the same general assignment from course management: "You are to act as a consultancy team. Based on the assignment you get from your company, define a problem that is not trivial. Suggest a plausible solution to this problem in an academic report."

Each team presents the whole scope of the project for the company representatives on three occasions (problem formulation, mid-project reporting, final product). During the project students visit the company several times. Planning, setting up meetings, conducting interviews, and utilizing other types of data collection are important parts of the skills training.

Our third active learning activity is teamwork. As touched upon earlier, our students have quite a lot of knowledge from courses in, for example, project management, team leadership, and human resource management (HRM). In the CPIM course they are challenged with an assignment where the final product is a large academic report (approx. 60 pages) written collaboratively. Building on their general teamwork experience, we explicitly add writing to their repertoire of teamwork skills. 
Our approach to writing has, since we launched the master's program, been connected to the notion of tangible communication. We argue that in an industrial master's program students are supposed to actually build a product. In this case, the written report is the product.

Inspired by design thinking at Stanford University (Carleton et al., 2013; Leifer, 2010), we have launched the concepts of prototyping and protostorming. In prototyping seminars, the students present their drafts and get feedback from teachers, industrial clients, and peers. The seminars are aimed at strengthening the incentive for peer-peer learning by focusing on tangible communication (show and talk). By prototyping and protostorming, with a focus on unfinished presentations of ideas and prototypes, we believe we have created an atmosphere where both teamwork processes and the writing process are in focus.

By implementing PBL, authentic case methodology, and teamwork, we have set the stage and created structures for active learning in a project-based course, where the students formulate and solve a real-world change project. In the CPIM course we have put the written report center stage in the teamwork process (prototyping a product). In the following we concentrate on the addition of CW tools to this teamwork setting and how these tools enhance the teamwork. For further details on the program design and authentic cases used in our master's program, see Blomkvist \& Uppvall (2012a, b).

\section{Purpose and research questions}

Our purpose is to investigate how the introduction of CW concepts and tools has affected the teamwork process in a project-based course where collective text production is a central component.

Our research questions are as follow:

1. Did the students use the CW tools, and if so, how did they use them?

2. How did CW influence teamwork activities (including teamwork management)?

3. Did the introduction of CW tools help create sustainable teamwork?

We use a range of methods to analyze and discuss our data (see below). The first question is answered by using quantitative methods, the second by using a qualitative approach, and the third by connecting our analysis to findings from research on project management, team leadership, and HRM. We focus on three aspects of sustainability in team performance: productivity, cohesion, and learning (Thompson, 2011).

\section{CW tools in engineering education}

Engineering education is constantly challenged by demands from industry and society. In particular, engineering education today is faced with an increased demand to educate students who can transform technical expertise into tangible results in complex environments (e.g., Crawley et al., 2014). As a response, a growing number of engineering curricula offer learning activities that mirror the complexity and collaborative reality of engineering professionals (Berglund, 2012; Crawley et al., 2014). In line with these trends, several authors have also stressed the increased demand on students' ability to collaboratively create written documentation (e.g., in order to share information and conduct systematic evaluations of products and processes; Gimenez \& Thondhlana, 2012; Henderson \& De Silva, 2006). In the specific engineering setting of the present study-industrial management-the amount of writing assignments, the importance of developing and evaluating texts, and the ability to coordinate organization-wide initiatives through written documentation could be argued to be even higher. Hence, increased knowledge on how the CW process is managed and how it affects teamwork seems to be a critical aspect in the design of contemporary learning activities in most engineering education areas.

Despite these arguments, and a reported frequent use of CW in both engineering education and among engineering professionals (Henderson \& De Silva, 2006; Wheeler \& McDonald 2000), the systematic knowledge on CW in engineering education is still limited, and results based on context-rich empirical studies are particularly rare (e.g., Gimenez \& Thondhlana, 2012).

A common obstacle in research on $\mathrm{CW}$ is the inconsistency in the nomenclature and taxonomy (Gimenez \& Thondhlana, 2012; Lowry et al., 2004). The present study applies the taxonomy developed by Lowry et al. (2004). Their work represents a comprehensive attempt to create a common taxonomy and nomenclature for scholars and practitioners in terms of CW activities, strategies, control modes, work models, and roles. 
For the aim of this study, the CW strategies Lowry et al. described in relation to teams' different writing tasks are central. That is, the students' choice of different CW strategies could have a strong influence on the teamwork in the studied projects. Based on prior research, Lowry et al. classified five major CW strategies: group single-author writing, sequential single-author writing, parallel writing-horizontal division, parallel writing-stratification, and reactive writing.

The first two CW strategies classified by Lowry et al. (2004) are described as attractive because they reduce complexity by only allowing one author to have access to the produced text at a given moment. The group single-author writing strategy lets one author write the whole text for the group. For simple tasks, small groups, and situations where the intentions of the group are clear, this single-author writing strategy could be highly efficient and style consistent. Contrary, when the task is sizeable, the team needs to learn from the writing and the intentions of the text need to be negotiated, this strategy has obvious limitations. The sequential single-author writing strategy makes use of only one writer at a time, letting each author sequentially build up the text until the last author finalizes the work. For small groups, simple writing tasks, and situations where gathering the group is difficult, this writhing strategy could be beneficial due to the ease of planning and coordination. However, limitations of this strategy relate to the coordination of content and style of the final text. In addition, text production could be inefficient if individual writers end up acting as bottlenecks.

The third and fourth CW strategies in Lowry et al.'s (2004) taxonomy, parallel writing-horizontal division and parallel writing-stratification, on the other hand, have been argued to support efficiency by allowing high-volume input through the concurrent work of authors. Through the parallel writing-horizontal division strategy, high-volume input is obtained by randomly allowing sections of the text to be developed simultaneously by the authors. This provides opportunities for efficiency and high-volume output and for moderate-complexity writing tasks to be easily divided. The downside, however, comes in terms of risks of authors producing overlapping work, challenges in planning and coordination, and the failure to capitalize on individual talents. The parallel writing-stratification strategy, in contrast, actively takes advantage of a group's diverse set of skills by assigning particular roles to different authors. Therefore, this strategy also provides the possibility for efficiency and high-volume output. The structure and division of tasks among the authors in the writing process (e.g., writer, editor, coordinator, etc.) also reduce the risk of redundancy and stylistic differences. However, the demands on planning and coordination are described as the highest among the different CW strategies.

Finally, the reactive writing strategy allows all authors to write simultaneously in all sections of the text. Each author can react and engage a consensus during the writing process, thus also setting the stage for creativity in the creation of the text. However, the limitations come in terms of coordination. For larger groups the possibility for active coordination must be seen as limited.

Although the work by Lowry et al. (2004) represents an important contribution to our continuous understanding of CW in both education and industry, it mainly represents theoretical models, and empirical studies conducted in specific contexts are still lacking (Gimenez \& Thondhlana, 2012).

One exemption to this is the study by Gimenez \& Thondhlana (2012), who investigated the use of CW in courses at four engineering schools in the United Kingdom. The study used multiple data sources to investigate the role of CW, what CW represented, and the dynamics of CW in the projects.

In the present study, our purpose is to investigate how the introduction of CW concepts and tools has affected the teamwork process in a project-based course where collective text production is a central component. Hence, this research aims to increase our understanding of CW by empirically studying students' use of CW in a contemporary and relevant context of engineering education.

\section{Method}

The paper builds on the CPIM students' reflections on the challenges of CW in a teamwork setting. As a part of the course examination, we asked the students to write individual papers to evaluate the usability of the CW tools in relation to the group project. We gave them the following assignment:

Provide a short individual report covering the insights and challenges related to the process of collaborative writing (CW). Can concepts from the field of CW help create sustainability on an individual/group level when working on these types of projects (as in the CPIM course)?

To introduce CW and create a common nomenclature, we presented a lecture on CW tools and strategies and distributed the following articles that explain and discuss CW: 
- Building a Taxonomy and Nomenclature of Collaborative Writing to Improve Interdisciplinary Research and Practice (Lowry et al., 2004)

- Collaborative Writing in Engineering: Perspectives from Research and Implications for Undergraduate Education (Gimenez \& Thondhlana, 2012)

We chose these articles after conducting a literature review on CW. The work by Lowry et al. (2004) still seems to represent the most comprehensive attempt to converge the research on CW. Given our focus on teamwork, the definitions and CW strategies that Gimenez \& Thondhlana (2012) provided fit particularly well in the context of engineering education. Thus, the two articles were the students' background information when they were asked to reflect on CW tools and teamwork. Their reflections, based on the concepts from these articles, served as our primary data when we were answering our research questions.

In total, the data consisted of 77 individual reflection papers with lengths of at least 2 and at most 3 pages. These papers represent over 200 pages of reflective texts, with a specific focus on the CW process among 12 student teams. We argue that this data set represents a unique source with the potential to provide valuable insights into the use of CW for teamwork-based activities in engineering education. Therefore, we provide quotes from our participants when discussing our findings. We analyzed the material in two stages according to the students' use of CW tools in their projects.

First, in relation or our first research question, the material was carefully coded using constructs from the literature on CW. The themes and codes for CW strategies and document control were based on the constructs that Lowry et al. (2004) presented. The analysis of $C W$ writing activities used themes from Gimenez \& Thondhlana (2012).

In the second stage, which is in relation to our second and third research questions, we adopted a more open approach, using both the complete material and the reduced (coded) material to interpret the students' accounts on the relationships between CW tool use and both teamwork management and teamwork dynamics. We used concepts from project management and team leadership theory to analyze whether and how the students used CW tools and strategies to manage teamwork activities. Finally, we analyzed the sustainability of the teamwork by looking for evidence of sustainable team performance. We evaluated this based on each team's use of CW tools and strategies to increase productivity, cohesion, and learning in the teams (Thompson, 2011).

In the following, we present the results for each of our three research questions. We then end provide a summative conclusion with suggestions for future research on the use of CW tools in teamwork.

\section{The students' use of CW tools}

In this part, we present and discuss the results regarding our first research question (Did the students use CW tools, and if so, how did they use them?) These results are mainly presented in a quantitative format, following Lowry et al.'s (2004) taxonomy.

Regarding the students' use of CW strategies, the summarized results are presented in Table 1 below.

The most frequently applied CW strategy was the parallel writing-horizontal division writing, which $82 \%$ of the students applied. This strategy was applied almost twice as frequently as either of the two next-most-frequently used CW strategies: reactive writing (45\%) and parallel writing-stratified division writing (43\%). Single-author writing was applied by 38\% of students, with an even distribution between group single-author writing (19\%) and sequential single-author writing (19\%).

These results confirm that the students actively and heavily used CW tools to manage their writing activities in the course. All the students except 4 were able to identify and clearly describe how the various types of CW strategies were used in relation to their group's collaborative writing process.

Regarding the CW strategies that the students used throughout their projects, the high proportion of parallel writing-horizontal division writing was expected. This strategy is effective for projects that require a high volume and fast input (Lowry et al., 2004). Given that the course is characterized by its large student groups,

Table 1. Students' use of CW strategies.

\begin{tabular}{|c|c|c|c|c|c|}
\hline \multicolumn{6}{|c|}{ Strategy (Lowry et al., 2004) } \\
\hline \multirow{2}{*}{ Strategy } & \multicolumn{2}{|c|}{ Single-author writing } & \multicolumn{2}{|c|}{ Parallel writing } & \multirow{2}{*}{ Reactive writing } \\
\hline & Group & Sequential & Horizontal division & Stratified division & \\
\hline Sum $(n=77)$ & 15 & 15 & 63 & 33 & 35 \\
\hline$\%$ & $19 \%$ & $19 \%$ & $82 \%$ & $43 \%$ & $45 \%$ \\
\hline
\end{tabular}


heavy workloads, and high volume of output, the parallel writing-horizontal division writing strategy could be argued to be the most logical choice. All groups used a parallel strategy, at least in some stage, in their writing processes to cope with the size of the given assignment.

Furthermore, these results also confirm what Gimenez \& Thondhlana (2012) found regarding the dynamic aspects of CW applied in students' group work. However, our analysis indicates a more emphasized process logic. That is, while the results of Gimenez \& Thondhlana (2012) mainly connected CW strategies to the writing of different parts of a report, our results indicate that the strategies applied more to the managerial aspects of handling a process-specifically, from problem formulation (creativity), toward handling various authors' contributions, and verifying the report's quality and the logic of its reasoning while meeting a deadline (complexity).

\section{The role of $\mathrm{CW}$ in teamwork}

In this part of the paper, we turn to the second research question (How did CW influence teamwork activities (including teamwork management)?).

As discussed above, the students used CW actively, and issues related to the management of the CW tools were prominent in the students' reflections. In the following, we move toward a qualitative analysis by focusing on these managerial aspects. We use well-known concepts from the management and teamwork literature (in italics) when analyzing our students' reflections (the same concepts are present in the literature of the students' earlier courses in project management and team leadership; e.g., Maylor, 2010; Thompson, 2011).

In all teamwork, as our students are well aware, planning is a key component. In the students' reflections, we can see a strong agreement regarding the importance of planning and replanning. There is a clear link between shifts in project structure and shifts in CW strategies.

As expected, a large part of the planning activities was about setting objectives for the project. Because the written report is the outcome of these projects (as is typical for management consultant work), many of the project objectives were set in the context of writing. In addition, many of the group's internal objectives were focused on the text itself: its structure and quality. Students used their knowledge of effective teams and transformed that knowledge into CW strategies.

In early parts of a project, students typically struggle with breaking down the overall project objectives into subtasks. This aspect had a huge impact on CW activities in the course. Students simultaneously worked to define the industrial problem, learned from theories related to the problem, and wrote texts to share new knowledge; this is described in our data as a highly complex managerial challenge. Examples of such situations include students' varying abilities to accept uncertainty, subgroups' varying abilities to develop strong group dynamics, and issues of acceptance regarding the fact that some of the work would not be useful with regard to the projects' outcomes. These factors are all interesting and complex aspects of both teamwork and CW.

Decisions regarding roles, including the appointment of leaders, are central aspects of the team-leadership literature, but they are also frequently highlighted in resent $\mathrm{CW}$ research. The students in our study often referred to these aspects as critical when discussing difficulties or when trying to overcome obstacles related to coordination and complexity in their projects.

In addition, several groups deliberately changed their leadership based on what challenges different phases of the project put on the team, either by replacing the leader or by adopting a different leadership style. Students noted that different writing activities (such as drafting, producing literature overviews, and final editing) affected the perceived need for leadership. Most clearly, the leader needed the ability to socially engage all members during problem formulation and drafting (including objectives), to engage in interpersonal relations, and to provide motivation to the group and to individual students when the complexity of the text grew.

The CW tools also influenced project organization and structure. Students used CW strategies to achieve critical goals within their projects. Most students had used patterns similar to those described in the CW literature (Lowry et al., 2004) in earlier projects of this type to achieve goals such as outputting a high volume of text and overcoming limitations on physically writing together. However, having a common nomenclature in CW seems to increase teamwork management activity. A toolbox of structures directly intended for the type of work that students actually do on most assignments-namely, write collaboratively-enhances students' abilities to actively use the knowledge and skills they have obtained from e.g. prior project management courses, as reflected upon in the quote below by one of the students participating in the study:

$\mathrm{CW}$ is something that has been commonly used throughout my academic education, however, this is actually the first time 1 have reflected over it. I believe that it is very important to reflect and analyze your working methods, both what can be improved and what have been performed perfectly, in order to improve your abilities. Therefore, 1 believe that this exercise is important and it is also quite strange that 1 never got it before. 
IT tools are an integral part in all teamwork management. Obviously, software and IT tools are of great importance in collaborative writing practices. In the literature, researchers mainly focus on advances and positive outcomes (e.g., Zhou et al., 2012). When our students reflected on theses aspects from a team management perspective, the outcomes of IT tools were less clear. Some students struggled to find IT tools that offered sufficient richness in communication. This often led to less use of IT tools, as one of its main benefits (the ability to work asynchronously) was not achieved in practice.

However, there are also many positive examples of teams that actively used IT tools in their collaborative writing. It seems as the most common benefit of IT tools was their use in final editing and adjustments for cohesion. Interestingly, this was sometimes described as a face-to-face approach in which each author had his or her own computer. In this way, teams could overcome the challenges associated with having a single author make the final adjustments and the restrictions on communication using these IT tools when physically separated.

Lastly, we would like to touch upon an issue that every team has to manage: quality assurance.

We want to highlight the fact that a high proportion of students emphasized that they used CW tools to reach the expected quality of their final texts. Our results indicate that students' access to models and nomenclature regarding $\mathrm{CW}$ enhanced both the process and the outcome of their texts. These $\mathrm{CW}$ tools, in a basic manner, seemed to help students to plan, keep track of, and evaluate the links between how they managed the team and the progression of the quality in their reports. In the quote below, one of the students discussed these aspects:

Besides realizing the challenges and difficulties that can occur when six people are trying to write a report together there were also hidden benefits. What we realized in the CPIM course was that when writing together we could identify gaps and flaws in our solution. This helped us elaborate more on our analysis and as a result we were able to refine our initial solutions. Furthermore, the collaborative writing helped us truly understand the analysis and the solution, something that is validated by the literature as well.

\section{Sustainable teamwork}

So far, we have established that our students actively used CW tools and strategies and that CW significantly enhanced teamwork management. In this section, we turn to the inner workings of the team-also known as teamwork dynamics-and discuss how that relates to CW. We address the third research question (Did the introduction of $\mathrm{CW}$ tools help create sustainable teamwork?).

In line with the CW literature, high-performing groups that conduct CW must be able to simultaneously effectively organize the CW work and develop the group's dynamic processes. The overall aim is to achieve sustainable teamwork. In other words, teamwork must lead to sustainable group performance during and after the project.

As mentioned above, sustainable team performance can be evaluated based on three aspects: productivity, cohesion, and learning (Thompson, 2011).

To achieve high productivity, teams must be able to adapt, change, and adjust project goals. One of the fundamental characteristics of the CPIM course is the ambiguity that is inherent in students' assignments. This means that no team can reach a high level of performance without actively managing change and adaptation. Therefore, teams also need to develop the capability to handle change and adaption to meet the project's objectives and to achieve sustainable performance.

For most teams, using the CW tools and knowledge seemed important in facilitating change, as illustrated in the quote below from one of the students:

Our project benefitted from adjusting $C W$ strategy based on how much joint decision and convergence was needed based on what section was written and in what phase we were in. Shifting control mode and roles brought issues such as lack of consensus, differences in style and lack of familiarity to information up to the surface, stimulating an iterative process of $\mathrm{CW}$ activities where drafting and reviewing in led to brainstorming and convergence on brainstorming, that in turn led to revising and editing.

Change in complex projects is also dependent on cohesion among team members. Most teams in our study articulated a strong need for face-to-face meetings to facilitate communication. Successful work was often reported as a result of frequent and long meetings of the whole group. Although some members questioned the usefulness of these meetings, they generally realized the meetings' value later in the project. This need for a common view (cohesion) shared by all project team members is illustrated in the quote below form one of the students: 
The group needed to come to a consensus on how to delimit the study to make it feasible to conduct in the short period of time available. This was in fact one of the main issues throughout the project, i.e. to ensure that all group members had the same idea of the tasks that needed to be done and that they were done in a coherent manner.

However, when communication fails and cohesion becomes weak, it is only a matter of time before mistakes are made; this can include overlapping work when group members are unaware of what others are doing. In these situations, the articulated knowledge of different CW strategies-the acquired nomenclature-was reported to be important. Teams use this knowledge to agree on structural changes, overcome these types of issues, and achieve higher effectiveness in their work.

Regarding learning, the third aspect of team performance, we can conclude that our students' use of CW knowledge leads to good performance through their abilities to learn from work and develop their working modes. First, most teams had a strong focus on communication. The urge to reach higher levels of richness in communication was also common; this led teams to experiment with developing hybrid CW strategies. A typical example was the management of writing in pairs or trios using an overall parallel strategy. Second, students described that using CW tools made members more involved in all parts of the projects; they perceived this use as positive affecting team members' commitment to the project-thus creating trust. Because trust is built on the perceived fulfillment of another person's expectations, this aspect of CW in the teams was highly valuable. Trusting relationships are often described as proof of strong team performance, especially because the division of tasks seldom results in an even distribution of workloads at all times; members need trust to manage a balance between give and take over time in their projects.

However, it should also be mentioned that teams did not always succeeded in terms of workload distribution. From a CW perspective, editing work in the final stages often led to situations in which members with high capacity in this area were experiencing that they had to put in more effort than others.

In addition, there were also some concrete examples of increased transparency, resulted from the use of CW tools, that helped teams manage typical aspects of student teamwork. One such aspect was related to social loafing or free riders, as shown below in the quote from one of the students:

$I$ would argue that the CW method used was the major factor influencing our teamwork, so that we could avoid social loafing. The CW method we used ensured that everybody had a specific task to accomplish, and no one could free ride on this project.

Finally, we would also like to touch upon another meaning of the term sustainable teamwork: teamwork skills and methods that are explicit and reproducible. Sustainability, in this sense, would mean that the use of CW tools also can influence students' future teamwork and that the acquired CW knowledge can be transferred to other settings.

For obvious reasons, we don't have any data on how CW will influence our students' future teamwork assignments. However, there is a strong indication that CW in fact has influenced the students' views on teamwork, as they frequently noted the eye-opening quality of CW. Before acquiring this CW knowledge, they struggled with low team performance due to nonexistent CW structure. Many students expressed frustration regarding the fact that they had not been introduced to CW earlier in their education. Based on these testimonials, we argue that the introduction of CW tools will likely increase team performance in the long term. In the quote below, one of the students claimed that CW not only enhanced the teamwork process itself but also could be viewed as a tool for providing deeper learning and knowledge management, which could be labeled knowledge and skill retention:

What we can see from our personal experience along with the theories developed in the field of CW is that even though it may be more time consuming, it is another way of analyzing your findings, enhancing your solution and gaining further understanding of your solution. In other words, it's a form of a knowledge creation process. Creating and managing knowledge is consultancy firms' greatest assets and thus any means to foster this should be seen as of importance. Successful knowledge management is key for creating synergies in firm and reaching synergies is the long-term perspective and the foundation for sustainable growth.

\section{Conclusion: CW as a tool for active learning}

Our purpose was to investigate how the introduction of CW concepts and tools affected the teamwork process in a project-based course in which collective text production played a central part.

Regarding the first research question (Did the students use the CW tools, and if so, how did they use them?) and the second (How did CW influence teamwork activities (including teamwork management)?), we can conclude that yes, they certainly did use the CW tools, and it had a positive influence on teamwork activities. 
Students in the CPIM course used CW tools extensively. The introduction of CW opened up the black box of writing activities in student projects. For example, it facilitated students' ability to express writing-related issues and helped students to identify the need for, and the direction of, changes in their collaborative writing setups. As such, CW contributed positively to our active learning package by making a large part of the teamwork explicit so that students could reflect on it.

We also answered the third research question (Did the introduction of CW tools help create sustainable teamwork?) through our investigation. The CW tools helped to create sustainable teamwork in the sense that they enhanced the three criterions of team performance: productivity, cohesion, and learning. By introducing CW tools, we gave our students a deeper knowledge regarding teamwork. That is, by making CW an explicit teamwork activity, we argue that we have enhanced their abilities to continuously learn and perform writing-centered teamwork in both educational and professional settings.

In sum, our contribution highlights the role that CW tools can play in enhancing teamwork performance and managing teamwork in projects. We did not investigate whether these CW tools actually created better collective texts, although we believe that they did. However, we can say for certain that the explicit use of CW tools in this setting created a vocabulary for collective writing efforts and positively influenced the management of teamwork in a sustainable direction.

Based on our study, we propose that future research could be aimed at deepen the understanding of how to enhance sustainability in teamwork settings by using CW as a management tool. Our study could be used as the basis for investigations regarding which CW tools are most suitable for various teamwork projects. It would be especially interesting to determine whether CW tools can be used to enhance knowledge and skill retention in teamwork projects. Thus, we are quite confident that CW has a lot of promising possibilities in both educational and professional settings.

\section{References}

Barrows, H. S., \& Tamblyn, R. H. (1980). Problem-based learning: an approach to medical education. New York: Springer Publishing.

Berglund, A. (2012). Do we facilitate an innovative learning environment? Student efficacy in two engineering design projects. Global Journal of Engineering Education, 14(1), 27-33.

Biggs, J. B., \& Tang, C. (2007). Teaching for quality learning at university (3rd ed.). Berkshire: McGraw-Hill.

Blomkvist, P., \& Uppvall, L. (2012a). A chain is only as strong as its weakest link: Managing change in the curriculum of industrial management education. International Journal of Industrial Engineering and Management, 3(2), 53-65.

Blomkvist, P., \& Uppvall, L. (2012b). Learning to love ambiguity: authentic live case methodology in industrial management education. International Journal of Case Method Research \& Application, 24(4), 272-285.

Carleton, T., Cockayne, W., \& Tahvanainen, A. (2013). Playbook for strategic foresight and innovation. Stanford: University of Stanford.

Cheong, F. (2008). Using a problem-based learning approach to teach an intelligent systems course. Journal of Information Technology Education, 7(1), 47-60.

Crawley, E. F., Malmqvist, J., Östlund, S., Brodeur, D. R., \& Edström, K. (2014). Rethinking Engineering Education: the CDIO approach (2nd ed.). New York: Springer.

Crawley, E., Malmqvist, J., Ostlund, S., \& Brodeur, D. (2007). Rethinking engineering education. The CDIO Approach, 302 , 60-62.

Edström, K., \& Kolmos, A. (2014). PBL and CD10: complementary models for engineering education development. European Journal of Engineering Education, 39(5), 539-555. http://dx.doi.org/10.1080/03043797.2014.895703.

Gimenez, J., \& Thondhlana, J. (2012). Collaborative writing in engineering: perspectives from research and implications for undergraduate education. European Journal of Engineering Education, 37(5), 471-487. http://dx.doi.org/10.1080/03043797.2012.714356.

Henderson, P., \& De Silva, N. (2006). A narrative approach to collaborative writing: a business process model. In Proceedings of 8th International Conference on Enterprise Information Systems (ICEIS), Paphos, Cyprus. Retrieved in 9 December 2016, from http:// citeseerx.ist.psu.edu/viewdoc/summary?doi=10.1.1.62.8495.

Leifer, L. (2010). PIEp Workshop: changing mindset, improving creativity and innovation in engineering education. Stanford: Stanford University.

Lowry, P. B., Curtis, A., \& Lowry, M. R. (2004). Building a taxonomy and nomenclature of collaborative writing to improve interdisciplinary research and practice. Journal of Business Communication, 41(1), 66-99. http://dx.doi.org/10.1177/0021943603259363.

Maylor, H. (2010). Project management (4th ed.). Essex: Pearson Education.

Porter, M. E. (1985). Competitive advantage: creating and sustaining superior performance. New York: FreePress.

Thompson, L. L. (2011). Making the Team: a guide for managers (4th ed.). Harlow: Pearson Education.

Wheeler, E., \& McDonald, R. (2000). Writing in engineering courses. Journal of Engineering Education, 89(4), 481-486. http://dx.doi. org/10.1002/j.2168-9830.2000.tb00555.x.

Zhou, W., Simpson, E., \& Domizi, D. P. (2012). Google docs in an out-of-class collaborative writing activity. International Journal on Teaching and Learning in Higher Education, 24(3), 359-375. 